\title{
Lattice-form dependent orbital shape and charge disproportionation in charge- and orbital-ordered manganites
}

\author{
D. Okuyama, ${ }^{1,2}$ Y. Tokunaga, ${ }^{2}$ R. Kumai, ${ }^{3}$ Y. Taguchi, ${ }^{1}$ T. Arima,,${ }^{4,5}$ and Y. Tokura ${ }^{1,2,3,6}$ \\ ${ }^{1}$ Cross-Correlated Materials Research Group (CMRG), ASI, RIKEN, Wako 351-0198, Japan \\ ${ }^{2}$ Multiferroics Project, ERATO, Japan Science and Technology Agency (JST), c/o RIKEN, Wako 351-0198, Japan \\ ${ }^{3}$ National Institute of Advanced Industrial Science and Technology (AIST), Tsukuba 305-8562, Japan \\ ${ }^{4}$ Institute of Multidisciplinary Research for Advanced Materials, Tohoku University, Sendai 980-8577, Japan \\ ${ }^{5}$ RIKEN SPring-8 Center, Hyogo, Japan \\ ${ }^{6}$ Department of Applied Physics, University of Tokyo, Tokyo 113-8656, Japan
}

(Dated: October 25, 2018)

\begin{abstract}
The orbital shapes and charge disproportionations at nominal $\mathrm{Mn}^{3+}$ and $\mathrm{Mn}^{4+}$ sites for the chargeand orbital-ordered phases have been studied on half-doped manganites $\operatorname{Pr}\left(\mathrm{Sr}_{0.1} \mathrm{Ca}_{0.9}\right)_{2} \mathrm{Mn}_{2} \mathrm{O}_{7}$ and $\mathrm{Eu}_{0.5} \mathrm{Ca}_{1.5} \mathrm{MnO}_{4}$ with double-layer and single-layer Mn-O networks, respectively, by means of xray structural analyses, in comparison with $\operatorname{Pr}_{0.5} \mathrm{Ca}_{0.5} \mathrm{MnO}_{3}$ with the pseudo cubic network. In a single-layer $\mathrm{Eu}_{0.5} \mathrm{Ca}_{1.5} \mathrm{MnO}_{4}$ system, the $\left(y^{2}-z^{2}\right) /\left(z^{2}-x^{2}\right)$-type orbital shape is observed, while the $\left(3 y^{2}-r^{2}\right) /\left(3 x^{2}-r^{2}\right)$-type orbital shape in a pseudo cubic $\mathrm{Pr}_{0.5} \mathrm{Ca}_{0.5} \mathrm{MnO}_{3}$ system. In a double-layer $\operatorname{Pr}\left(\mathrm{Sr}_{0.1} \mathrm{Ca}_{0.9}\right)_{2} \mathrm{Mn}_{2} \mathrm{O}_{7}$ system, the orbital shape is found to undergo a large change upon thermally induced rotation of orbital stripe. Furthermore, clear charge disproportionation is observed for the pseudo cubic and double-layer systems, while not in the single-layer system. These results indicate that the orbital shape and charge disproportionation are sensitive to the dimension of Mn-O network.
\end{abstract}

PACS numbers: 75.30.-m, 61.05.cp, 75.47.Lx

\section{INTRODUCTION}

Charge and orbital order (CO-OO) in mixed-valence manganites with perovskite-related structures has been attracting great interest since the $\mathrm{CO}-\mathrm{OO}$ makes a strong impact on crystallography, magnetism, and electrical conduction 1 . For example, magnetic-field induced melting of long-range and/or short-range $\mathrm{CO}-\mathrm{OO}$ results in colossal magnetoresistance ${ }^{2}$. Huge changes in electrical conduction due to the melting of CO-OO have been reported with the application of other external stimuli, such as an electric field, x-ray, light, and pressure $e^{3,4,5,6}$. Many diffraction and theoretical studies have reported the checkerboard type charge order of $\mathrm{Mn}^{3+}$ and $\mathrm{Mn}^{4+}$ ions with charge disproportionation and stripe-type orbital order, explaining a complex antiferromagnetic spin order at low temperatures in half-doped manganites $7,8,9,10,11,12,13,14,15,16$. On the other hand, another model with less distinct charge disproportionation has also been proposed $17,18,19,20,21,22,23,24,25$. For example, taking into account the on-site Coulomb interaction, Brink et al. have suggested $\frac{17}{17}$ that maximum value of charge disproportionation is as little as $20 \%$. First principle calculation by Mahadevan et al. have also shown 18 that the charge disproprtionation is almost negligible for $\mathrm{La}_{0.5} \mathrm{Sr}_{1.5} \mathrm{MnO}_{4}$ compound. Herrero-Martin et al. have inferred 21 from the resonant $\mathrm{x}$-ray scattering data that the charge disproportionation of $\mathrm{Nd}_{0.5} \mathrm{Sr}_{0.5} \mathrm{MnO}_{3}$ is about $20 \%$. These different models have raised an important question about the nature of CO state.

Another issue to be clarified is the orbital shape at $\mathrm{Mn}^{3+}$ ion in the CO-OO phase. Radaelli et al. suggested by powder neutron and synchrotron x-ray diffraction studies that the $\left(3 y^{2}-r^{2}\right) /\left(3 x^{2}-r^{2}\right)$-type orbital order takes place in $\mathrm{La}_{0.5} \mathrm{Ca}_{0.5} \mathrm{MnO}_{3}{ }^{26}$. $\mathrm{La}_{0.5} \mathrm{Sr}_{1.5} \mathrm{MnO}_{4}$ was also studied as another CO-OO system by resonant $\mathrm{x}$-ray scattering and $\mathrm{x}$-ray linear dichroism methods 10,27 ; the latter 27 strongly suggested the $\left(y^{2}-z^{2}\right) /\left(z^{2}-x^{2}\right)$ type orbital shape at $\mathrm{Mn}^{3+}$ ion. It is an unsolved problem why the orbital shape of $\mathrm{La}_{0.5} \mathrm{Ca}_{0.5} \mathrm{MnO}_{3}$ and $\mathrm{La}_{0.5} \mathrm{Sr}_{1.5} \mathrm{MnO}_{4}$ appear different. One obvious difference between these two materials is the dimensionality of $\mathrm{MnO}_{6}$ network. The variation of the dimensionality has already been reported $28,29,30$ to affect the CO-OO state significantly in terms of correlation length, but its effect on the orbital shape should be investigated systematically. To clarify these issues, we have made systematic investigations on the charge disproportionation and orbital shape in the CO-OO phases of half-doped manganites with various $\mathrm{Mn}-\mathrm{O}$ networks (single-, double-, and infinite-layered $\mathrm{MnO}_{2}$ sheets) by means of x-ray structure analysis. The results indicate that the charge disproportionation is in reality much smaller than unity, and that the orbital shape critically depends on the lattice form, in particular on the dimensionality of Mn-O network. As far as we know, there has been no experimental investigation on the charge disproportionation for the layered manganites thus far.

The investigated materials in this study are $\mathrm{Pr}_{0.5} \mathrm{Ca}_{0.5} \mathrm{MnO}_{3}, \quad \operatorname{Pr}\left(\mathrm{Sr}_{0.1} \mathrm{Ca}_{0.9}\right)_{2} \mathrm{Mn}_{2} \mathrm{O}_{7}, \quad$ and $\mathrm{Eu}_{0.5} \mathrm{Ca}_{1.5} \mathrm{MnO}_{4}$ with pseudo cubic, double-layer, and single-layer Mn-O networks, respectively. We chose these materials with good size matching of the ionic radii at the $A$-sites to reduce the effect of quenched disorder (randomness) as much as possible ${ }^{31,32,33}$. Another important point in selecting the target materials is that the well-defined orthorhombic distortion of all these materials enables us to obtain the single-domain orbital- 
ordered state as locked by the orthorhombicity. The concomitant CO-OO is observed at $T_{\mathrm{CO}}$ which is higher than the CE-type antiferromagnetic ordering in every case ${ }^{33.37}$. In $\mathrm{Pr}_{0.5} \mathrm{Ca}_{0.5} \mathrm{MnO}_{3}$ and $\mathrm{Eu}_{0.5} \mathrm{Ca}_{1.5} \mathrm{MnO}_{4}$, the CO-OO transitions take place at $T_{\mathrm{CO}} \sim 230 \mathrm{~K}$ and $325 \mathrm{~K}$, and the CE-type antiferromagnetic order with spins pointing along the $b$-axis is established at $T_{\mathrm{N}} \sim 170 \mathrm{~K}$ and $120 \mathrm{~K}$, respectively $34,35,36,37$. The ferromagnetic zig-zag chain is parallel to the $b$-axis in $\mathrm{Pr}_{0.5} \mathrm{Ca}_{0.5} \mathrm{MnO}_{3}$, and to $a$-axis in $\mathrm{Eu}_{0.5} \mathrm{Ca}_{1.5} \mathrm{MnO}_{4}$, respectively. In contrast, successive $\mathrm{CO}-\mathrm{OO}$ transitions are observed at $T_{\mathrm{CO} 1} \sim 370 \mathrm{~K}$ and $T_{\mathrm{CO} 2} \sim 315 \mathrm{~K}$ in $\operatorname{Pr}\left(\mathrm{Sr}_{0.1} \mathrm{Ca}_{0.9}\right)_{2} \mathrm{Mn}_{2} \mathrm{O}_{7}$. The propagation direction of stripe-type orbital order spontaneously rotates from along the $a$-axis to along the $b$-axis at $T_{\mathrm{CO} 2}$; this appears as a generic feature of $\mathrm{CO}-\mathrm{OO}$ double-layer manganites ${ }^{33}$. CE-type antiferromagnetic order with spins pointing along $b$-axis grows below $T_{\mathrm{N}} \sim 153 \mathrm{~K}^{38}$, and the ferromagnetic zig-zag chain is along $a$-axis. In both of the $\mathrm{Eu}_{0.5} \mathrm{Ca}_{1.5} \mathrm{MnO}_{4}$ and $\operatorname{Pr}\left(\mathrm{Sr}_{0.1} \mathrm{Ca}_{0.9}\right)_{2} \mathrm{Mn}_{2} \mathrm{O}_{7}$, CO-OO produces clear anisotropy of electronic states, typically manifested by the optical conductivity spectra, in which the oscillator strength at low energy region is more suppressed in orbital-stripe direction than in orbital zig-zag chain direction $\underline{37,38}$

\section{EXPERIMENTS AND ANALYSES}

We have performed structure analysis for single crystals of $\mathrm{Eu}_{0.5} \mathrm{Ca}_{1.5} \mathrm{MnO}_{4}$ and $\operatorname{Pr}\left(\mathrm{Sr}_{0.1} \mathrm{Ca}_{0.9}\right)_{2} \mathrm{Mn}_{2} \mathrm{O}_{7}$ grown by the floating zone method. The crystals were crashed into small grains. X-ray diffraction experiments were performed for twin-free single crystals with a diameter of about $30 \mu \mathrm{m}$ on the beamline BL-1A at Photon Factory in KEK, Japan. The photon energy of the incident x-rays was tuned at $18 \operatorname{keV}(\lambda=0.688 \AA)$. Xray beams were shaped into a square with the size of $300 \mu \mathrm{m} \times 300 \mu \mathrm{m}$ by a collimator, which is enough larger than the size of samples. To detect x-rays, a large cylindrical imaging plate was utilized. Temperature was controlled by a nitrogen gas stream cryostat. The intensity data were operated to the F-tables by using the program of Rapid-Auto, Rigaku Corp. and MSC. The Sir2004 program ${ }^{39}$ was employed for the direct method. We used the program of CrystalStructure of Rigaku Corp. and MSC. for analyzing the crystal structure from the F-table. Absorption effects were not corrected, because the $\mu r$ were enough small in each sample. For $\mathrm{Eu}_{0.5} \mathrm{Ca}_{1.5} \mathrm{MnO}_{4}$ and $\operatorname{Pr}\left(\mathrm{Sr}_{0.1} \mathrm{Ca}_{0.9}\right)_{2} \mathrm{Mn}_{2} \mathrm{O}_{7}$, $\mu$ r are $0.40\left(\mu=134.511 \mathrm{~cm}^{-1}\right)$ and $0.44\left(\mu=146.027 \mathrm{~cm}^{-1}\right)$, respectively. To check this assumption, we tried to correct the absorption effects. No difference was observed for the structural data obtained with and without the absorption correction.

For the analysis, we used thus determined crystal structure data for $\mathrm{Eu}_{0.5} \mathrm{Ca}_{1.5} \mathrm{MnO}_{4}$ and $\operatorname{Pr}\left(\mathrm{Sr}_{0.1} \mathrm{Ca}_{0.9}\right)_{2} \mathrm{Mn}_{2} \mathrm{O}_{7}$, and the published data for
$\mathrm{Pr}_{0.5} \mathrm{Ca}_{0.5} \mathrm{MnO}_{3}$ by Goff et al. .2 $^{2}$. We adopt the localized-orbital picture, assuming a priori the strong electron-lattice interaction $\underline{40}$. Then, the breathing and Jahn-Teller distortion modes, $Q_{1}, Q_{2}$, and $Q_{3}$, can be related with charge disproportionation and orbital shape $\stackrel{41}{1}$, and defined as

$$
\left(\begin{array}{l}
Q_{1} \\
Q_{2} \\
Q_{3}
\end{array}\right)=1 / \sqrt{6}\left(\begin{array}{ccc}
\sqrt{2} & \sqrt{2} & \sqrt{2} \\
\sqrt{3} & -\sqrt{3} & 0 \\
-1 & -1 & 2
\end{array}\right)\left(\begin{array}{c}
d_{x}-\bar{d} \\
d_{y}-\bar{d} \\
d_{z}-\bar{d}
\end{array}\right),
$$

where $d_{x}, d_{y}$, and $d_{z}$ are bond lengths between Mn and $\mathrm{O}$ ions along the $x, y$, and $z$-axes, respectively, which are shown as schematic views of distorted $\mathrm{MnO}_{6}$ octahedra in Fig. 1 (a). $\bar{d}=1.956(2) \AA$ is the average bond length for $\mathrm{Mn}^{3.5+}$ (Ref. 42). The approximate valences of Mn sites can be calculated from the bond valence sum ${ }^{43}$, given by $V=\sum_{i} \exp \left(\left(d_{0}-d_{i}\right) / B\right)$. Here, $V$ is the calculated valence, $d_{i}$ is the $i$-th Mn-O bond length, $d_{0}=1.760$ $\AA$ for $\mathrm{Mn}^{3+}$, and $1.753 \AA$ for $\mathrm{Mn}^{4+}$, and $B \sim 0.37 \AA$ Basically, the bond valence sum is appropriate for ions with formal valence of integer such as $\mathrm{Mn}^{3+}$ and $\mathrm{Mn}^{4+}$ ions. To estimate the bond valence sum of intermediate valence states, we use a quadratic fit with the bond valence sum curves for $\mathrm{Mn}^{3+}$ and $\mathrm{Mn}^{4+}$, as shown in Fig. 11 (b) $\underline{44}$. On the other hand, it has been well known as Kanamori representation ${ }^{41}$ that the orbital shape is related with the Jahn-Teller $Q_{2}$ and $Q_{3}$ modes, as shown in Fig. 1 (c). In the $Q_{2}-Q_{3}$ plane, the orbital state is thus described as $\left|d_{\theta}\right\rangle=\cos \left(\frac{\theta}{2}\right)\left|d_{3 z^{2}-r^{2}}\right\rangle+\sin \left(\frac{\theta}{2}\right)\left|d_{x^{2}-y^{2}}\right\rangle$. Similar analysis based on the bond valence sum and the Kanamori representation has been applied to manganites in some literatures $22,45,46,47$.

\section{RESULTS}

In Fig. 2 we show a typical diffraction pattern of $\mathrm{Eu}_{0.5} \mathrm{Ca}_{1.5} \mathrm{MnO}_{4}$ in the CO-OO phase. Besides the fundamental Bragg spots, superlattice spots (indicated by arrows) due to cooperative Jahn-Teller distortion are clearly observed. The intensities of the superlattice reflections are three orders of magnitude weaker than those of the fundamental Bragg spots. There was no diffuse scattering intensity discerned around the superlattice spots, indicating the minimal effect of quenched disorder ${ }^{48}$. In Figs. 3 (a), (b), and (c), observed structure factor $\left(F_{\text {obs }}\right)$ is plotted against calculated one $\left(F_{\text {cal }}\right)$ for $\mathrm{Eu}_{0.5} \mathrm{Ca}_{1.5} \mathrm{MnO}_{4}$ at $295 \mathrm{~K}$, for $\operatorname{Pr}\left(\mathrm{Sr}_{0.1} \mathrm{Ca}_{0.9}\right)_{2} \mathrm{Mn}_{2} \mathrm{O}_{7}$ at $330 \mathrm{~K}$, and at $295 \mathrm{~K}$, respectively. The obtained reliability factors are $R=1.78 \%, R_{w}=2.25 \%$ at CO-OO phase of $\mathrm{Eu}_{0.5} \mathrm{Ca}_{1.5} \mathrm{MnO}_{4}, \quad R=3.35 \%, R_{w}=4.52 \%$ at $\mathrm{CO} 1$ phase $\left(T_{\mathrm{CO} 2} \leqq T \leqq T_{\mathrm{CO} 1}\right)$, and $R=2.95 \%, R_{w}=3.80$ $\%$ at $\mathrm{CO} 2$ phase $\left(T \leqq T_{\mathrm{CO} 2}\right)$ of $\operatorname{Pr}\left(\mathrm{Sr}_{0.1} \mathrm{Ca}_{0.9}\right)_{2} \mathrm{Mn}_{2} \mathrm{O}_{7}$, respectively. Detailed crystal structural data are listed in APPENDIX, and CIF-files are available at elsewhere $\stackrel{49}{\text {. }}$.

Figure 4 (a) shows a schematic view of the CO-OO state of $\operatorname{Pr}_{0.5} \mathrm{Ca}_{0.5} \mathrm{MnO}_{3}$, which is based on the crystal structural data by Goff et al $\stackrel{22}{=}$, in which the space group 

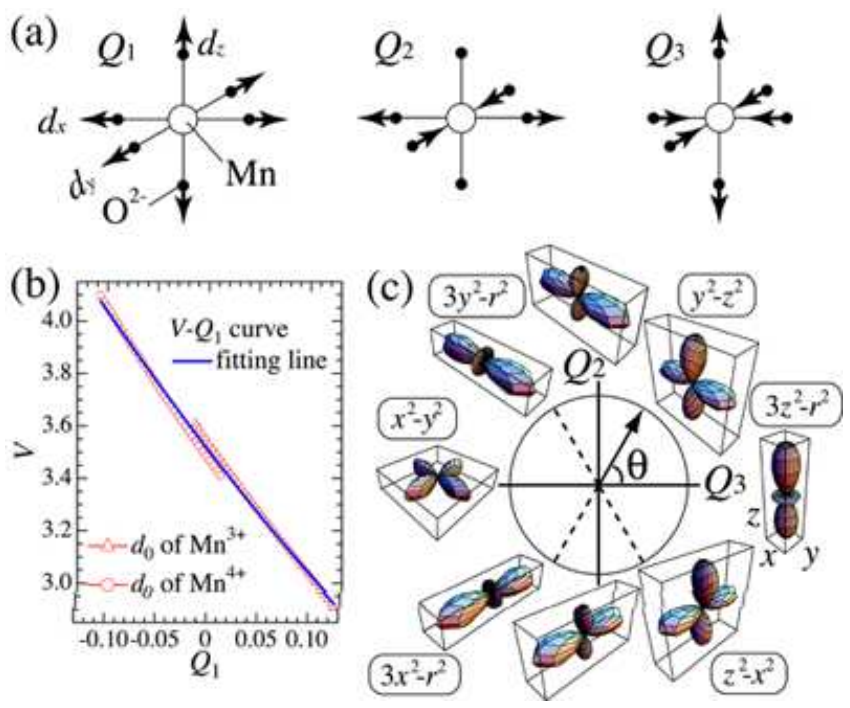

FIG. 1: (Color online) (a) Relevant distortion modes, $Q_{1}, Q_{2}$, and $Q_{3}$ of a $\mathrm{MnO}_{6}$ octahedron. Arrows indicate shifts of $\mathrm{O}^{2-}$ ions. (b) $V-Q_{1}$ curves calculated with using the bond valence sum formula. Triangles (circles) show the relation calculated for the $d_{0}$ value appropriate for an integer valence of $\mathrm{Mn}^{3+}$ $\left(\mathrm{Mn}^{4+}\right)$. A solid line indicates a quadratic fitting with the values of triangles and circles. (c) Preferred orbital shapes of an $e_{g}$ electron with respect to the $Q_{2}-Q_{3}$ plane (Kanamori representation ${ }^{41}$ ).

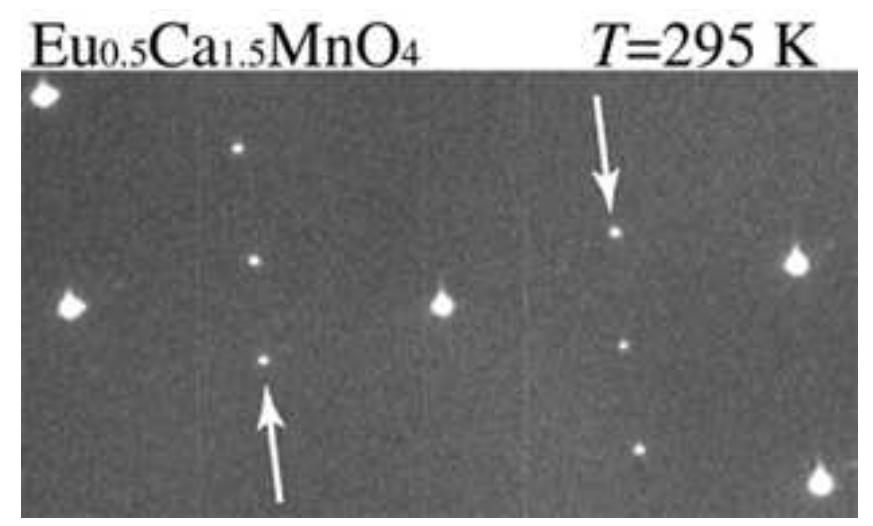

FIG. 2: (Color online) Typical diffraction image of $\mathrm{Eu}_{0.5} \mathrm{Ca}_{1.5} \mathrm{MnO}_{4}$ in the CO-OO phase $(295 \mathrm{~K})$. The arrows indicate the superlattice reflections, whose intensities are 3 orders of magnitude weaker than those of the bright fundamental spots.

and the lattice parameters at $10 \mathrm{~K}$ are reported to be $P 2_{1} / m$ (No.11), $a=5.43499(3) \AA, b=10.8700(2) \AA$, and $c=7.488923(6) \AA$, respectively. Orbital stripes appear along the $a$-axis, which is parallel to the diagonal-glide plane of the orbital disordered phase. The orbital shapes at $\mathrm{Mn}^{3+}$ and $\mathrm{Mn}^{4+}$ sites of $\operatorname{Pr}_{0.5} \mathrm{Ca}_{0.5} \mathrm{MnO}_{3}$ obtained by the present analysis are indicated in Figs. 5 (a) and (b), respectively, in which the radius of the circle is related to $Q_{1}\left[Q_{1}=-0.1(0.1)\right.$ corresponds to $\left.V \sim+4(+3)\right]$, and the direction of each arrow indicates the orbital state

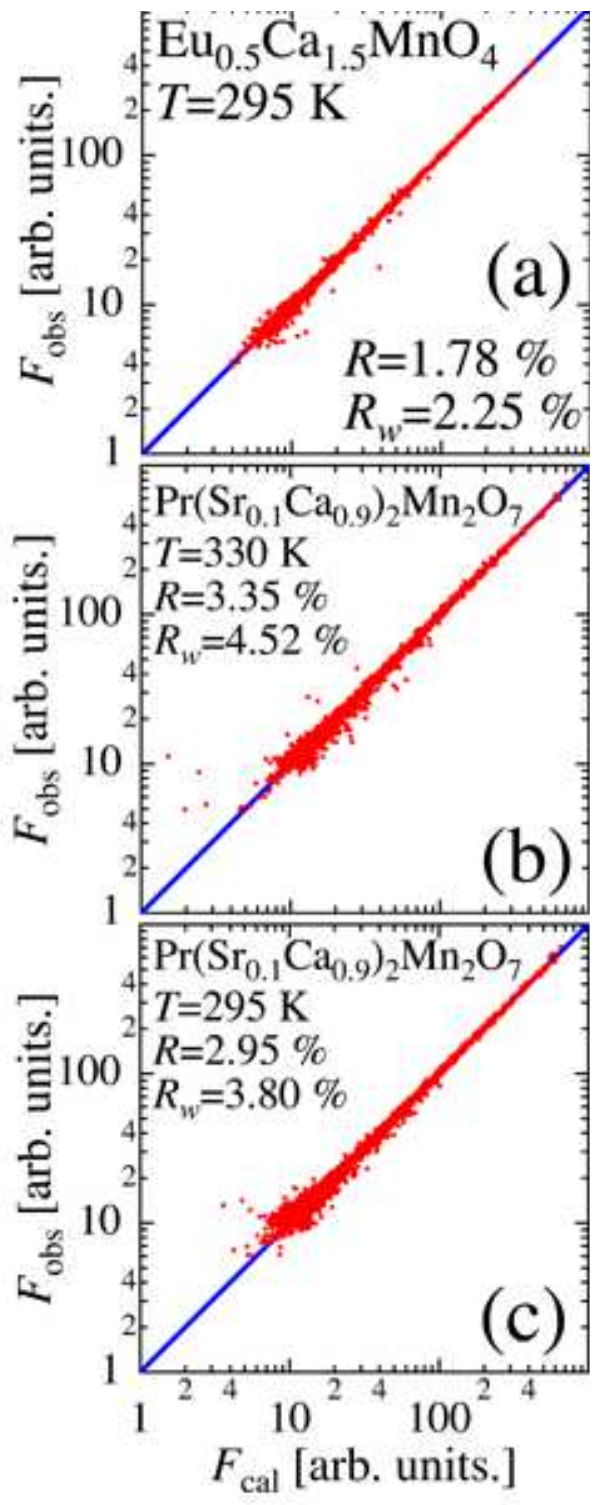

FIG. 3: (Color online) The comparison between observed $\left(F_{\text {obs }}\right)$ and calculated $\left(F_{\text {cal }}\right)$ structure factor of $(\mathrm{a})$ $\mathrm{Eu}_{0.5} \mathrm{Ca}_{1.5} \mathrm{MnO}_{4}$ at $295 \mathrm{~K}$, (b) $\mathrm{CO} 1$ phase $(330 \mathrm{~K})$ of $\operatorname{Pr}\left(\mathrm{Sr}_{0.1} \mathrm{Ca}_{0.9}\right)_{2} \mathrm{Mn}_{2} \mathrm{O}_{7}$, and (c) $\mathrm{CO} 2$ phase $(295 \mathrm{~K})$ of $\operatorname{Pr}\left(\mathrm{Sr}_{0.1} \mathrm{Ca}_{0.9}\right)_{2} \mathrm{Mn}_{2} \mathrm{O}_{7}$, respectively.

$\left|d_{\theta}\right\rangle$ calculated from $Q_{2}$ and $Q_{3}$. There are two crystallographically inequivalent $\mathrm{Mn}^{3+}$ sites termed Mn1 and $\mathrm{Mn} 2$, and one $\mathrm{Mn}^{4+}$ site (Mn3) in the CO-OO phase. The obtained values of $d_{x}, d_{y}, d_{z}, Q_{2}, Q_{3}$, and $V$ are listed in Table $\mathbb{⿷}^{0}$. From these values, charge disproportionation between nominal $\mathrm{Mn}^{3+}$ and $\mathrm{Mn}^{4+}$ sites is estimated to be roughly $22 \%$, which is very close to the value reported for $\mathrm{Nd}_{0.5} \mathrm{Sr}_{0.5} \mathrm{MnO}_{3}$ using resonant X-ray scattering technique $\stackrel{21}{ }$. Furthermore, for the Mn1 and Mn2 sites, the $\left(3 y^{2}-r^{2}\right) /\left(3 x^{2}-r^{2}\right)$-type orbital shapes are obtained. For the Mn3 site, by contrast, the $Q_{2}$ and $Q_{3}$ values are small as compared to $Q_{1}$ value, indicating the least Jahn-Teller distortion or unlifted orbital de- 
(a) ProsCais $\mathrm{MnO}, \quad$ orbital order type $-\left(3 y^{2}-r^{2}\right) /\left(3 x^{2}-r^{2}\right)$ (b) $\mathrm{Eu}_{5} \mathrm{Ca}_{1.5} \mathrm{MnO}_{4} \quad$ orbital order type $-\left(y^{2}-z^{2}\right) /\left(x^{2}-z^{2}\right)$

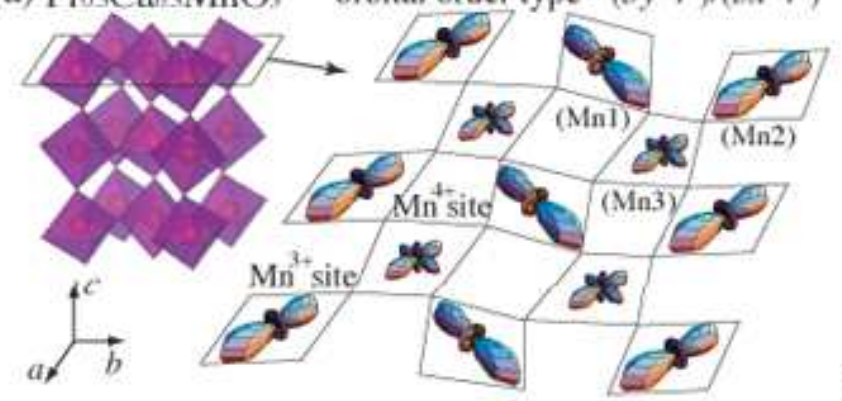

(cl) $\mathrm{Pr}\left(\mathrm{Sr}_{0} \mathrm{Ca}_{0}\right)_{2} \mathrm{Mn}_{2} \mathrm{O}_{7} \quad \mathrm{CO} 1$ phase

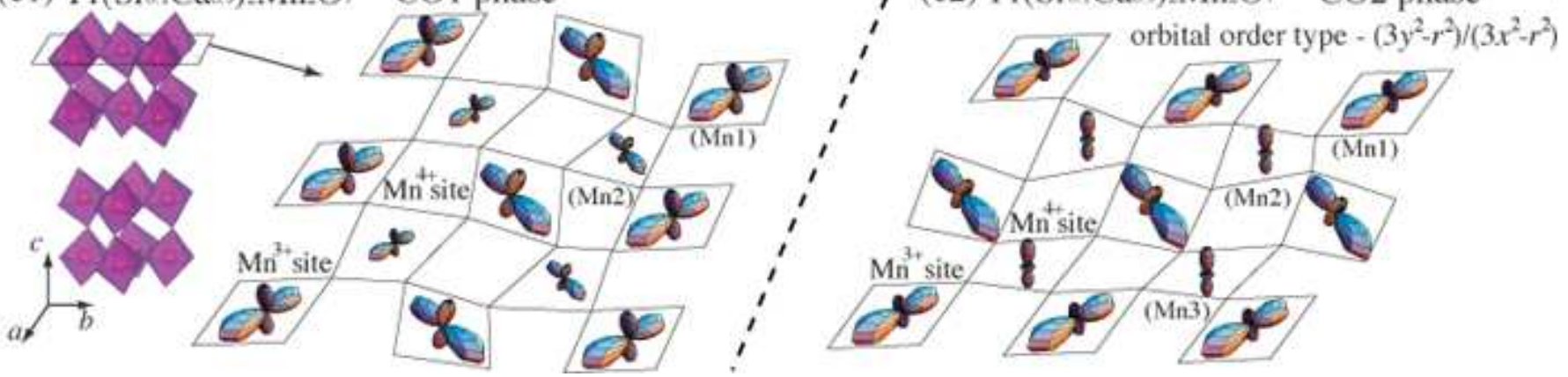

FIG. 4: (Color online) The CO-OO states schematically displayed for (a) $\mathrm{Pr}_{0.5} \mathrm{Ca}_{0.5} \mathrm{MnO}_{3}$, (b) $\mathrm{Eu}_{0.5} \mathrm{Ca}_{1.5} \mathrm{MnO}_{4}$, and (c1) CO1 phase $(330 \mathrm{~K})$ and $(\mathrm{c} 2) \mathrm{CO} 2$ phase $(295 \mathrm{~K})$ of $\operatorname{Pr}\left(\mathrm{Sr}_{0.1} \mathrm{Ca}_{0.9}\right)_{2} \mathrm{Mn}_{2} \mathrm{O}_{7}$. The crystal structural data reported by Goff et al. ${ }^{22}$ were used for the analysis of $\operatorname{Pr}_{0.5} \mathrm{Ca}_{0.5} \mathrm{MnO}_{3}$.

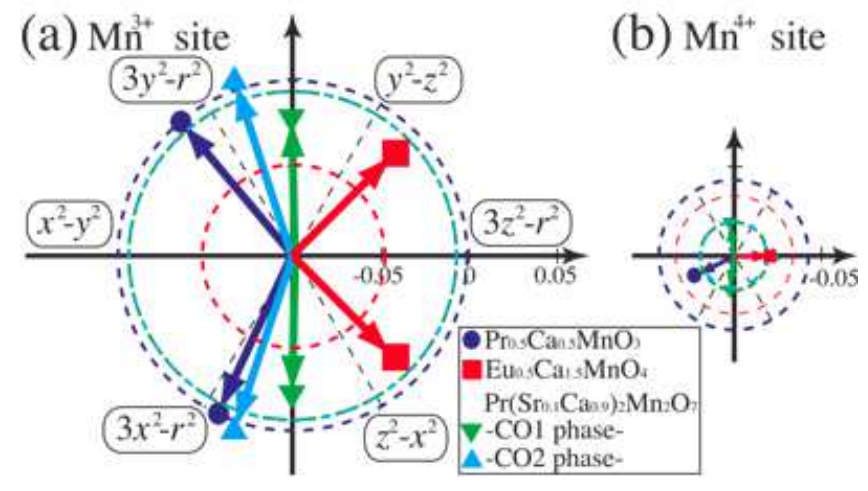

FIG. 5: (Color Online) Orbital shapes and charge states of (a) $\mathrm{Mn}^{3+}$ and (b) $\mathrm{Mn}^{4+}$ sites. The radius of the circle is related to the $\mathrm{Mn}$ valence. The directions of arrows indicate the corresponding orbital shape.

generacy with almost isotropic electron density, namely, $\rho(\boldsymbol{r}) \propto \lambda\left|\Psi_{3 z^{2}-r^{2}}\right|^{2}+\left|\Psi_{x^{2}-y^{2}}\right|^{2}$, with $\lambda$ slightly smaller than 1.

The CO-OO state of $\mathrm{Eu}_{0.5} \mathrm{Ca}_{1.5} \mathrm{MnO}_{4}$ with single-layer Mn-O network is schematically illustrated in Fig. 4 (b). The crystal structural analysis showed that the space group is Pmnb (No.62) of orthorhombic crystal system, and the lattice parameters are $a=10.6819(7)$ $\AA, b=5.4071(3) \AA$, and $c=11.7018(11) \AA$ at $295 \mathrm{~K}$, respectively. Orbital stripes line up along the $b$-axis, which is perpendicular to the diagonal-glide plane, giv-
TABLE I: Distortion of $\mathrm{MnO}_{6}$ octahedra in $\operatorname{Pr}_{0.5} \mathrm{Ca}_{0.5} \mathrm{MnO}_{3}$ at $10 \mathrm{~K}^{22}$. $d_{i}$ and $Q_{j}(i=x, y, z ; j=2,3)$ are in unit of $\AA$. The space group is $P 2_{1} / m$ (No.11), and the lattice parameters are $a=5.43499(3) \AA, b=10.8700(2) \AA$, and $c=7.488923(6) \AA$, respectively.

\begin{tabular}{ccccccc}
\hline \hline & $d_{x}$ & $d_{y}$ & $d_{z}$ & $Q_{2}$ & $Q_{3}$ & $V$ \\
\hline Mn1 & $2.039(6)$ & $1.930(5)$ & $1.9061(6)$ & $0.077(4)$ & $-0.064(5)$ & $3.48(2)$ \\
Mn2 & $1.911(8)$ & $2.027(5)$ & $1.9216(3)$ & $-0.082(5)$ & $-0.039(6)$ & $3.53(3)$ \\
Mn3 & $1.933(5)$ & $1.948(6)$ & $1.914(3)$ & $-0.011(6)$ & $-0.021(6)$ & $3.72(4)$ \\
\hline \hline
\end{tabular}

ing rise to the observed optical anisotropy ${ }^{37}$. The obtained parameters are listed in Table III About 8\% charge disproportionation between $\mathrm{Mn}^{3+}$ and $\mathrm{Mn}^{4+}$ sites is observed, which should be interpreted as indicating that the actual charge disproportionation is almost negligible, taking into account the semi-quantitative nature of the bond valence sum analysis. The negligible charge disproportionation is in excellent accord with the theoretical prediction ${ }^{18}$ for the single-layer compound $\mathrm{La}_{0.5} \mathrm{Sr}_{1.5} \mathrm{MnO}_{4}$. For Mn1 site, the $\left(y^{2}-z^{2}\right) /\left(x^{2}-z^{2}\right)$ type orbital shape is observed, as shown in Fig. 5 , This orbital shape is also consistent with the result of x-ray linear dichroism experiment 27 . In contrast, for Mn2 site, $Q_{2}$ and $Q_{3}$ values are small with respect to $Q_{1}$ value, indicating almost isotropic electron density $\rho(\boldsymbol{r}) \propto \lambda\left|\Psi_{3 z^{2}-r^{2}}\right|^{2}+\left|\Psi_{x^{2}-y^{2}}\right|^{2}$, with $\lambda$ slightly larger than 1. Therefore, Mn1 and Mn2 sites can be regarded as nominal $\mathrm{Mn}^{3+}$ and $\mathrm{Mn}^{4+}$ site in the light of orbital 
TABLE II: Distortion of $\mathrm{MnO}_{6}$ octahedra in $\mathrm{Eu}_{0.5} \mathrm{Ca}_{1.5} \mathrm{MnO}_{4}$ at $295 \mathrm{~K}$. The space group is Pmnb (No.62) of orthorhombic crystal system, and the lattice parameters are $a=10.6819(7)$ $\AA, b=5.4071(3) \AA$, and $c=11.7018(11) \AA$, respectively.

\begin{tabular}{ccccccc}
\hline \hline & $d_{x}$ & $d_{y}$ & $d_{z}$ & $Q_{2}$ & $Q_{3}$ & $V$ \\
\hline Mn1 & $1.943(4)$ & $1.863(3)$ & $1.972(5)$ & $0.057(3)$ & $0.056(3)$ & $3.77(2)$ \\
Mn2 & $1.910(5)$ & $1.910(5)$ & $1.934(4)$ & $0.000(3)$ & $0.019(3)$ & $3.85(2)$ \\
\hline \hline
\end{tabular}

activity, albeit minimal charge disproportionation.

The pseudo cubic and single-layer compounds show clear contrast in orbital shape and charge disproportionation; $22 \%$ charge disproportionation and $\left(3 y^{2}-\right.$ $\left.r^{2}\right) /\left(3 x^{2}-r^{2}\right)$-type orbital shape of $\mathrm{Mn}^{3+}$ site for pseudo cubic, while negligibly small charge disproportionation and $\left(y^{2}-z^{2}\right) /\left(x^{2}-z^{2}\right)$-type orbital shape for single-layer. From the crystallographic point of view, the double-layer system has an intermediate structure between pseudo cubic and single-layer. We show in Fig. 4(c) schematic pictures of the CO-OO states of $\operatorname{Pr}\left(\mathrm{Sr}_{0.1} \mathrm{Ca}_{0.9}\right)_{2} \mathrm{Mn}_{2} \mathrm{O}_{7}$ with double-layer Mn-O network based on the structural parameters listed in Table III The space groups are Pbnm (No. 62) with $a=5.4087(2) \AA, b=10.9171(5) \AA$, and $c=19.2312(12) \AA$ at $330 \mathrm{~K}$ (CO1) and $A m 2 m$ (No. 38) with $a=10.8026(7) \AA, b=5.4719(4) \AA$, and $c=19.2090(10)$ $\AA$ at $295 \mathrm{~K}$ (CO2), respectively. In the CO1 phase, the orbital stripes along the $a$-axis are clearly seen, which is parallel to the diagonal-glide plane. We observe about $39 \%$ charge disproportionation in the CO1 phase. For Mn1 site, the orbital shape is of intermediate type between $\left(3 y^{2}-r^{2}\right) /\left(3 x^{2}-r^{2}\right)$ and $\left(y^{2}-z^{2}\right) /\left(z^{2}-x^{2}\right)$, and the similar orbital shape is obtained for Mn2 site (Fig. 5). $\operatorname{Pr}\left(\mathrm{Sr}_{0.1} \mathrm{Ca}_{0.9}\right)_{2} \mathrm{Mn}_{2} \mathrm{O}_{7}$ undergoes a transition with 90 -degree rotation of orbital stripes at $T_{\mathrm{CO} 2} \sim 315 \mathrm{~K}^{38}$. In the $\mathrm{CO} 2$ phase, the orbital stripes run along the $b$-axis, as clearly seen in Fig. 4 (c2), in accord with the previous report ${ }^{38}$. There are one $\mathrm{Mn}^{3+}$ site and two crystallographically inequivalent $\mathrm{Mn}^{4+}$ sites, termed respectively Mn1, Mn2, and Mn3, in the CO2 phase. The obtained charge disproportionation of about $39 \%$ is comparable with that of CO1 phase, whereas the $\left(3 y^{2}-r^{2}\right) /\left(3 x^{2}-r^{2}\right)$ type orbital shape as in $\operatorname{Pr}_{0.5} \mathrm{Ca}_{0.5} \mathrm{MnO}_{3}$ is suggested for the $\mathrm{Mn}^{3+}$ sites, as shown in Fig. 5. In both phases, the observed direction of orbital stripes is consistent with the optical anisotropy ${ }^{38}$.

\section{DISCUSSION}

While the stripe-type orbital pattern commonly observed in the three materials gives rise to the same CE-type magnetic ordering, the orbital shape does depend on the structural difference, and seems to be governed by the difference in the stacking-sequence of (rare-earth/alkaline-earth)-oxygen (AO) planes and $\mathrm{MnO}_{2}$ planes. Note that the AO plane contains apical oxygens of $\mathrm{MnO}_{6}$ octahedra. In the charge- and
TABLE III: Distortion of $\mathrm{MnO}_{6}$ octahedra at CO1 phase (330 $\mathrm{K})$ and $\mathrm{CO} 2$ phase $(295 \mathrm{~K})$ of $\operatorname{Pr}\left(\mathrm{Sr}_{0.1} \mathrm{Ca}_{0.9}\right)_{2} \mathrm{Mn}_{2} \mathrm{O}_{7}$. The space group is Pbnm (No. 62) and Am2m (No. 38) of orthorhombic crystal system at $330 \mathrm{~K}$ and $295 \mathrm{~K}$, respectively, and the lattice parameters are $a=5.4087(2) \AA, b=10.9171(5)$ $\AA$, and $c=19.2312(12) \AA$ at $330 \mathrm{~K}$, and $a=10.8026(7) \AA$, $b=5.4719(4) \AA$, and $c=19.2090(10) \AA$ at $295 \mathrm{~K}$, respectively.

\begin{tabular}{ccccccc}
\hline \hline $330 \mathrm{~K}$ & $d_{x}$ & $d_{y}$ & $d_{z}$ & $Q_{2}$ & $Q_{3}$ & $V$ \\
\hline Mn1 & $2.007(4)$ & $1.899(3)$ & $1.952(4)$ & $0.076(3)$ & $-0.001(3)$ & $3.53(2)$ \\
Mn2 & $1.898(4)$ & $1.925(5)$ & $1.908(4)$ & $0.019(3)$ & $-0.003(3)$ & $3.92(2)$ \\
\hline \hline 295 K & $d_{x}$ & $d_{y}$ & $d_{z}$ & $Q_{2}$ & $Q_{3}$ & $V$ \\
\hline Mn1 & $2.032(2)$ & $1.898(2)$ & $1.926(3)$ & $0.095(2)$ & $-0.032(2)$ & $3.53(2)$ \\
Mn2 & $1.901(2)$ & $1.901(2)$ & $1.929(3)$ & $0.000(2)$ & $0.023(2)$ & $3.92(2)$ \\
Mn3 & $1.905(2)$ & $1.905(2)$ & $1.924(3)$ & $0.000(2)$ & $0.016(2)$ & $3.91(2)$ \\
\hline \hline
\end{tabular}

orbital-disordered phase of $\mathrm{Pr}_{0.5} \mathrm{Ca}_{0.5} \mathrm{MnO}_{3}, \mathrm{MnO}_{6}$ octahedron is almost isotropic with slight compression along $c$-axis due to the pseudo cubic symmetry of the crystal structure ${ }^{36}$. Below the CO-OO transition, $e_{g}$ electrons tend to maximize the kinetic energy gain due to the local double exchange interaction with the neighboring $\mathrm{Mn}^{4+}$ $t_{2 g}$ spins on the $a b$-plane, and the $\left(3 y^{2}-r^{2}\right) /\left(3 x^{2}-r^{2}\right)$ type orbital shape is favored. In $\mathrm{Eu}_{0.5} \mathrm{Ca}_{1.5} \mathrm{MnO}_{4}$, by contrast, the bond length between $\mathrm{Mn}$ and apical oxygen is longer than that within the plane 49 even in the charge- and orbital-disordered phase at $360 \mathrm{~K}$. This is because a single $\mathrm{MnO}_{2}$ plane is negatively charged, and hence apical oxygen and rare-earth/alkaline-earth ions on the adjacent layers tend to be apart from and close to the $\mathrm{MnO}_{2}$ plane, respectively. The body-centered nature of the $\mathrm{K}_{2} \mathrm{NiF}_{4}$-like structure allows this type of local lattice distortion in a cooperative manner. (It should be noted that this lattice distortion is not driven by the Jahn-Teller interaction, but due to the purely lattice structural effect, as evidenced by the presence of similar lattice distortion in $\mathrm{La}_{2} \mathrm{NiO}_{4}{ }^{51}$ in which $\mathrm{Ni}^{2+}$ (with two $e_{g}$ electrons) with $S=1$ is Jahn-Teller inactive.) Therefore, the electron orbital extended along the $c$-axis is stabilized by such a distortion at high temperatures. As the temperature is lowered, however, $e_{g}$ electrons tend to favor the orbital shape extended within the $\mathrm{MnO}_{2}$ planes so as to gain the spin exchange energy, similarly to the case of $\operatorname{Pr}_{0.5} \mathrm{Ca}_{0.5} \mathrm{MnO}_{3}$, thereby establishing $\left(y^{2}-z^{2}\right) /\left(z^{2}-x^{2}\right)$-type orbital order at $T_{\mathrm{CO}}$. The structure of $\operatorname{Pr}\left(\mathrm{Sr}_{0.1} \mathrm{Ca}_{0.9}\right)_{2} \mathrm{Mn}_{2} \mathrm{O}_{7}$ compound can be viewed as intermediate between the single layer and infinite layer compounds. Therefore, it is likely that an intermediate orbital state between $\operatorname{Pr}_{0.5} \mathrm{Ca}_{0.5} \mathrm{MnO}_{3}$ and $\mathrm{Eu}_{0.5} \mathrm{Ca}_{1.5} \mathrm{MnO}_{4}$ is favored in the intermediate $\mathrm{CO} 1$ phase. In the CO2 phase, however, the $\left(3 y^{2}-r^{2}\right) /\left(3 x^{2}-\right.$ $\left.r^{2}\right)$-type orbital shape is realized as in the pseudo cubic case, in which the magnetic interaction as favoring the CE-type order may play a role.

As the layer number is increased, charge disproportionation increases from the smallest value of $8 \%$ for the single layer compound to $39 \%$ for the double layer ma- 
terial, and then rather decreases to $22 \%$ for the infinite layer compound. In the single layer system, the development of order parameter may be suppressed due to the enhanced fluctuation effect. In the double layer system, fluctuation effect would be reduced, and the larger charge disproportionation is observed. The reason why the observed charge disproportionation is smaller in the infinite layer material than in double layer compound is not clear at present, but the enhanced double exchange interaction in the infinite layer material due to the increased dimensionality might be the origin.

\section{SUMMARY}

In summary, we have revealed that the charge disproportionation between nominal $\mathrm{Mn}^{3+}$ and $\mathrm{Mn}^{4+}$ is in reality much smaller than unity, and in particular, negligible in single-layer system. This result is in contrast with the belief at the early stage of the research of the CO-OO phenomena, but in accord with the recent results $16,17,18,19,20,21,22,23,24,25$. This indicates that various interactions, such as electron-lattice, Coulomb repulsion, and magnetic interactions, should be taken into account to correctly understand the nature of chargeordered state. The orbital shape is different among the three compounds despite the same symmetry of the COOO pattern in a single $\mathrm{MnO}_{2}$ plane, structurally confirming the previous conclusions based on different experimental techniques 26,27 . The charge disproportionation and orbital shape in these materials are dominated by the dimension of Mn-O network, and the local environment of the apical oxygen seems to be particularly important.

\section{Acknowledgments}

The authors thank S. Ishiwata and Y. Tomioka for fruitful discussions. This study was performed with the approval of the Photon Factory Program Advisory Committee (No.2006S2-005).

\section{APPENDIX A: CRYSTAL-STRUCTURAL DATA}

We present the crystal structural data of $\mathrm{Eu}_{0.5} \mathrm{Ca}_{1.5} \mathrm{MnO}_{4}$ and $\operatorname{Pr}\left(\mathrm{Sr}_{0.1} \mathrm{Ca}_{0.9}\right)_{2} \mathrm{Mn}_{2} \mathrm{O}_{7}$. Table IV shows the distortion parameters $d_{x}, d_{y}, d_{z}, Q_{1}$, $Q_{2}, Q_{3}, V$, and $\theta$ of $\operatorname{Pr}_{0.5} \mathrm{Ca}_{0.5} \mathrm{MnO}_{3}$ calculated from the crystallographic data of Goff et al $\Omega^{22}$. The crystal structural data at $360 \mathrm{~K}$ (disordered phase) and 295 $\mathrm{K}$ (CO-OO phase) of $\mathrm{Eu}_{0.5} \mathrm{Ca}_{1.5} \mathrm{MnO}_{4}$ are shown in Table V and Fig. VI respectively. From these crystal data, the distortion parameters of $360 \mathrm{~K}$ and $295 \mathrm{~K}$ are calculated and summarized as Table VII For $\operatorname{Pr}\left(\mathrm{Sr}_{0.1} \mathrm{Ca}_{0.9}\right)_{2} \mathrm{Mn}_{2} \mathrm{O}_{7}$, the crystal structure data in disordered phase (at $405 \mathrm{~K}$ ) are presented in Table VIII. For two CO-OO phases, the data at $330 \mathrm{~K}$ in $\mathrm{CO} 1$ phase $\left(T_{\mathrm{CO} 2} \leqq T \leqq T_{\mathrm{CO} 1}\right)$ and at $295 \mathrm{~K}$ in $\mathrm{CO} 2\left(T \leqq T_{\mathrm{CO} 2}\right)$ are listed in Fig. [X] and Fig. $\mathrm{X}$, respectively. In Table XI, the distortion parameters at $405 \mathrm{~K}, 330 \mathrm{~K}$, and $295 \mathrm{~K}$ are reported. In these crystal structural data, $x, y$, and $z$ indicate the fractional coordinates. $g$ is the site-occupation number. Anisotropic atomic displacement parameters are represented as $U_{11}, U_{22}, U_{33}, U_{12}$, $U_{13}$, and $U_{23}$, while $B_{j}$ and $\left\langle u_{j}^{2}\right\rangle\left(B_{j}=8 \pi^{2} U_{j}=8 \pi^{2}\left\langle u_{j}^{2}\right\rangle\right)$ are the isotropic atomic displacement parameter and the mean square atomic displacement of the ion $j$, respectively. From the $B_{j}$, the Debye-Waller factor is expressed as $\exp \left(-B_{j}\left(\sin \theta_{K} / \lambda\right)^{2}\right)$, where $\theta_{K}$ and $\lambda$ are the Bragg angle and wave length, respectively.
1 Y. Tokura and N. Nagaosa, Science 288, 462 (2000).

2 Y. Tokura, Rep. Prog. Phys. 69, 797 (2006).

3 A. Asamitsu, Y. Tomioka, H. Kuwahara, and Y. Tokura, Nature 388, 50 (1997).

${ }^{4}$ V. Kiryukhin, D. Casa, J. P. Hill, B. Keimer, A. Vigliante, Y. Tomioka, and Y. Tokura, Nature 386, 813 (1997).

${ }_{5}^{5}$ M. Fiebig, K. Miyano, Y. Tomioka, and Y. Tokura, Science 280, 1925 (1998).

${ }^{6}$ Y. Moritomo, H. Kuwahara, Y. Tomioka, and Y. Tokura, Phys. Rev. B 55, 7549 (1997).

7 E. O. Wollan and W. C. Koehler, Phys. Rev. 100, 545 (1955).

8 J. B. Goodenough, Phys. Rev. 100, 564 (1955).

9 C. H. Chen and S-W. Cheong, Phys. Rev. Lett. 76, 4042 (1996).
10 Y. Murakami, H. Kawada, H. Kawata, M. Tanaka, T. Arima, Y. Moritomo, and Y. Tokura, Phys. Rev. Lett. 80, 1932 (1998).

11 I. V. Solovyev, and K. Terakura, Phys. Rev. Lett. 83, 2825 (1999).

12 T. Mutou and H. Kontani, Phys. Rev. Lett. 83, 3685 (1999).

13 C. H. Chen, S. Mori, and S-W. Cheong, Phys. Rev. Lett. 83, 4792 (1999).

14 D. Khomskii, and J. van den Brink, Phys. Rev. Lett. 85, 3329 (2000).

15 E. Dagotto, T. Hotta, and A. Moreo, Phys. Report. 344, 1 (2001).

16 Z. Popović and S. Satpathy, Phys. Rev. Lett. 88, 197201 (2002). 
17 J. van den Brink, G. Khaliullin, and D. Khomskii, Phys. Rev. Lett. 83, 5118 (1999).

18 P. Mahadevan, K. Terakura, and D. D. Sarma, Phys. Rev. Lett. 87, 066404 (2001).

19 G. Subías, J. García, M. G. Proietti, and J. Blasco, Phys. Rev. B 56, 8183 (1997).

20 J. García, M. C. Sánchez, G. Subías, and J. Blasco, J. Phys.: Condens. Matter 13, 3229 (2001).

21 J. Herrero-Martín, J. García, G. Subías, J. Blasco, M. Concepción Sánchez, Phys. Rev. B 70, 024408 (2004).

22 R. J. Goff and J. P. Attfield, Phys. Rev. B 70, 140404(R) (2004).

23 J. C. Loudon, S. Cox, A. J. Williams, J. P. Attfield, P. B. Littlewood, P. A. Midgley, and N. D. Mathur, Phys. Rev. Lett. 94, 097202 (2005).

${ }^{24}$ G. C. Milward, M. J. Calderón, and P. B. Littlewood, Nature 433, 607 (2005).

25 S. Cox, J. Singleton, R. D. Mcdonald, A. Migliori, and P. B. Littlewood, Nature Mater. 7, 25 (2008).

${ }^{26}$ P. G. Radaelli, D. E. Cox, M. Marezio, and S-W. Cheong, Phys. Rev. B 55, 3015 (1997).

27 D. J. Huang, W. B. Wu, G.Y. Guo, H.-J. Lin, T. Y. Hou, C. F. Chang, C. T. Chen, A. Fujimori, T. Kimura, H. B. Huang, A. Tanaka, and T. Jo, Phys. Rev. Lett. 92, 087202 (2004).

28 M. v. Zimmermann, J. P. Hill, D. Gibbs, M. Blume, D. Casa, B. Keimer, Y. Murakami, Y. Tomioka, and Y. Tokura, Phys. Rev. Lett. 83, 4872 (1999).

29 Y. Wakabayashi, Y. Murakami, Y. Moritomo, I. Koyama, H. Nakao, T. Kiyama, T. Kimura, Y. Tokura, and N. Wakabayashi, J. Phys. Soc. Jpn. 70, 1194 (2001).

30 O. Zachar, and I. Zaliznyak, Phys. Rev. Lett. 91, 036401 (2003).

31 Y. Tomioka and Y. Tokura, Phys. Rev. B 70, 014432 (2004).

32 R. Mathieu, M. Uchida, Y. Kaneko, J. P. He, X. Z. Yu, R. Kumai, T. Arima, Y. Tomioka, A. Asamitsu, Y. Matsui, and Y. Tokura, Phys. Rev. B 74, 020404(R) (2006).

33 Y. Tokunaga, T. J. Sato, M. Uchida, R. Kumai, Y. Matsui, T. Arima, and Y. Tokura, Phys. Rev. B 77, 064428 (2008).

34 Z. Jirák, S. Krupička, Z. Šimša, M. Dlouhá, and S. Vratislav, J. Magn. Magn. Mater. 53, 153 (1985).

35 Y. Tomioka, A. Asamitsu, H. Kuwahara, Y. Moritomo, and Y. Tokura, Phys. Rev. B 53, R1689 (1996).

36 Z. Jirák, F. Damay, M. Hervieu, C. Martin, B. Raveau, G. André, and F. Bourée, Phys. Rev. B 61, 1181 (2000).

37 Y. Tokunaga, R. Kumai, N. Takeshita, Y. Kaneko, J. P. He, T. Arima, and Y. Tokura, Phys. Rev. B 78, 155105 (2008).

38 Y. Tokunaga T. Lottermoser, Y. Lee, R. Kumai, M.
Uchida, T. Arima, and Y. Tokura, Nature Mater. 5, 937 (2006).

39 M. C. Burla, R. Caliandro, M. Camalli, B. Carrozzini, G. L. Cascarano, L. De Caro, C. Giacovazzo, G. Polidori, and R. Spagna, J. Appl. Cryst. 38, 381 (2005).

40 Effect of electron transfer interaction may affect the result based on the simple localized-orbital picture, in particular, in the two-dimensional case where the energy gain due to the anisotropic hopping becomes strongly orbitaldependent. Therefore, the obtained results might include some error at a quantitative level in a strict sense. However, in view of the excellent agreement of the obtained results with the result of Refs 18 27, the error would not be significant.

41 J. Kanamori, J. Appl. Phys. 31, S14 (1960).

42 The average bond length $\bar{d}$ for $\mathrm{Mn}^{3.5+}$ is estimated from the fitting of Valence-distance (Mn-O bond length) curves calculated by the bond valence sum of $\mathrm{Mn}^{3+}$ and $\mathrm{Mn}^{4+}$.

43 I. D. Brown and D. Altermatt, Acta Crystallogr. Sect. B 41, 244 (1985).

44 The calculated bond valence sum for oxygen shows a value of $-2 \pm 0.1$ for all materials, indicating that doped number is well included in the calculated nominal valence of $\mathrm{Mn}$ ions. However, it should be noted that doped holes have strong $\mathrm{O} 2 p$ character in reality.

45 J. Rodríguez-Carvajal, G. Rousse, C. Masquelier, and M. Hervieu, Phys. Rev. Lett. 81, 4660 (1998).

46 J.-S. Zhou, and J. B. Goodenough, Phys. Rev. Lett. 96, 247202 (2006).

47 E. J. Cussen, M. J. Rosseinsky, P. D. Battle, J. C. Burley, L. E. Spring, J. F. Vente, S. J. Blundell, A. I. Coldea, and J. Singleton, J. Am. Chem. Soc. 123, 1111 (2001).

48 Minimal disorder effect is also manifested by the absence of enhancement of the atomic displacement factors (see tables in APPENDIX), ensuring the validity of using bond valence sum analysis.

49 See EPAPS Document No. for CIF-files with crystal structural data. For more information on EPAPS, see http://www.aip.org/pubservs/epaps.html.

50 Averaged value of $V$ is 3.61 for $\operatorname{Pr}_{0.5} \mathrm{Ca}_{0.5} \mathrm{MnO}_{3}$, and is larger than the nominal value of 3.5. Similar tendency is found also for the single layer and the double layer compounds. This would be due to the compressed (stretched) nature of $\mathrm{Mn}-\mathrm{O}$ (rare-earth/alkaline-earth-O) bond and the resultant charge transfer from $\mathrm{Mn}$ site to the rareearth/alkaline-earth site.

51 J. D. Jorgensen, B. Dabrowski, S. Pei, D. R. Richards, and D. G. Hinks, Phys. Rev. B 40, 2187 (1989). 
TABLE IV: Distortion of $\mathrm{MnO}_{6}$ octahedra in $\operatorname{Pr}_{0.5} \mathrm{Ca}_{0.5} \mathrm{MnO}_{3}$ at $10 \mathrm{~K}^{22}$.

\begin{tabular}{lcccccccc}
\hline \hline & $d_{x}\left(\AA^{2}\right)$ & $d_{y}\left(\AA^{2}\right)$ & $d_{z}\left(\AA^{2}\right)$ & $Q_{1}$ & $Q_{2}$ & $Q_{3}$ & \multicolumn{1}{c}{$\theta$} \\
\hline Mn1 & $2.039(6)$ & $1.930(5)$ & $1.9061(6)$ & $0.004(4)$ & $0.077(4)$ & $-0.064(5)$ & $3.48(2)$ & $130(4)^{\circ}$ \\
Mn2 & $1.911(8)$ & $2.027(5)$ & $1.9216(3)$ & $-0.005(5)$ & $-0.082(5)$ & $-0.039(6)$ & $3.53(3)$ & $245(5)^{\circ}$ \\
Mn3 & $1.933(5)$ & $1.948(6)$ & $1.914(3)$ & $-0.042(6)$ & $-0.011(6)$ & $-0.021(6)$ & $3.72(4)$ & $21(2) \times 10^{\circ}$ \\
\hline \hline
\end{tabular}

TABLE V: The structure parameters of $\mathrm{Eu}_{0.5} \mathrm{Ca}_{1.5} \mathrm{MnO}_{4}$ in the disordered phase at $360 \mathrm{~K}$. The 3048 reflections were observed, and 966 of them are independent. The 29 variables were used for the refinement. The space group is $B m a b$ (No. 64) of orthorhombic crystal system. The latticce parameters are as follows: $a=5.3638(19) \AA, b=5.4088(9) \AA, c=11.738(2) \AA$. The reliability factors are $R=2.40 \%, R_{w}=2.55 \%, \mathrm{GOF}$ (Goodness of fit) $=1.062$.

\begin{tabular}{|c|c|c|c|c|c|c|}
\hline & site & $x$ & $y$ & $z$ & $g$ & $B\left(\AA^{2}\right)$ \\
\hline Eu1 & $8 f$ & 0 & $0.9933(4)$ & $0.64219(16)$ & $1 / 2$ & $0.645(15)$ \\
\hline Ca1 & $8 f$ & 0 & $0.9854(5)$ & $0.6427(2)$ & $3 / 2$ & $0.75(2)$ \\
\hline Mn & $4 a$ & 0 & 0 & 0 & 1 & $0.412(5)$ \\
\hline $\mathrm{O} 1$ & $8 e$ & $1 / 4$ & $3 / 4$ & $0.98777(8)$ & 1 & $1.097(19)$ \\
\hline \multirow[t]{2}{*}{$\mathrm{O} 2$} & $8 f$ & 0 & $0.9623(2)$ & $0.16570(7)$ & 1 & $1.51(2)$ \\
\hline & $U_{11}\left(\AA^{2}\right)$ & $U_{22}\left(\AA^{2}\right)$ & $U_{33}\left(\AA^{2}\right)$ & $U_{12}\left(\AA^{2}\right)$ & $U_{13}\left(\AA^{2}\right)$ & $U_{23}\left(\AA^{2}\right)$ \\
\hline Eu1 & $0.0111(8)$ & $0.00898(17)$ & $0.0044(2)$ & 0.0000 & 0.0000 & $0.00132(14)$ \\
\hline Ca1 & $0.0129(9)$ & $0.0097(2)$ & $0.0060(3)$ & 0.0000 & 0.0000 & $-0.00106(19)$ \\
\hline $\mathrm{Mn}$ & $0.0056(2)$ & $0.00414(4)$ & $0.00593(6)$ & 0.0000 & 0.0000 & $-0.00030(2)$ \\
\hline $\mathrm{O} 1$ & $0.0111(10)$ & $0.01142(19)$ & $0.0192(2)$ & $0.0028(3)$ & 0.0000 & 0.0000 \\
\hline $\mathrm{O} 2$ & $0.0314(11)$ & $0.0202(3)$ & $0.00583(15)$ & 0.0000 & 0.0000 & $-0.00107(19)$ \\
\hline
\end{tabular}

TABLE VI: The structure parameters of $\mathrm{Eu}_{0.5} \mathrm{Ca}_{1.5} \mathrm{MnO}_{4}$ in the charge- and orbital-ordered phase at $295 \mathrm{~K}$. The 13758 reflections were observed, and 5552 of them are independent. The 95 variables were used for the refinement. The space group is Pmnb (No. 62) of orthorhombic crystal system. The latticce parameters are as follows: $a=10.6819(7) \AA, b=5.4071(3) \AA$, $c=11.7018(11) \AA$. The reliability factors are $R=1.78 R_{w}=2.25 \mathrm{GOF}=1.058$.

\begin{tabular}{|c|c|c|c|c|c|c|}
\hline & site & $x$ & $y$ & $z$ & $g$ & $B\left(\AA^{2}\right)$ \\
\hline Eu1 & $4 c$ & $3 / 4$ & $0.004300(10)$ & $0.143400(10)$ & 0.25 & $0.513(16)$ \\
\hline Eu2 & $8 d$ & $0.49964(2)$ & $0.00800(3)$ & $0.35889(3)$ & 0.25 & $0.56(2)$ \\
\hline Eu3 & $4 c$ & $3 / 4$ & $0.504900(10)$ & $0.642900(10)$ & 0.25 & $0.370(19)$ \\
\hline Ca1 & $4 c$ & $3 / 4$ & $-0.016400(10)$ & $0.140700(10)$ & 0.75 & $0.28(2)$ \\
\hline $\mathrm{Ca} 2$ & $8 d$ & $0.49916(3)$ & $0.01430(3)$ & $0.35555(3)$ & 0.75 & $0.84(3)$ \\
\hline $\mathrm{Ca} 3$ & $4 c$ & $3 / 4$ & $0.530700(10)$ & $0.641700(10)$ & 0.75 & $0.417(11)$ \\
\hline Mn1 & $4 a$ & 0 & $1 / 2$ & $1 / 2$ & 1 & $0.354(14)$ \\
\hline $\mathrm{Mn} 2$ & $4 c$ & $3 / 4$ & $0.00604(5)$ & $0.49926(10)$ & 1 & $0.344(15)$ \\
\hline O1 & $8 d$ & $0.8753(3)$ & $0.2610(5)$ & $0.5134(2)$ & 1 & $0.91(2)$ \\
\hline $\mathrm{O} 2$ & $8 d$ & $0.6259(4)$ & $0.7579(7)$ & $0.4874(2)$ & 1 & $1.02(2)$ \\
\hline O3 & $4 c$ & $3 / 4$ & $0.0503(10)$ & $0.3359(3)$ & 1 & $1.02(4)$ \\
\hline $\mathrm{O} 4$ & $4 c$ & $3 / 4$ & $0.9599(13)$ & $0.6637(3)$ & 1 & $1.07(4)$ \\
\hline \multirow[t]{2}{*}{ O5 } & $8 d$ & $0.9992(2)$ & $0.5337(13)$ & $0.6678(4)$ & 1 & $1.62(5)$ \\
\hline & $U_{11}\left(\AA^{2}\right)$ & $U_{22}\left(\AA^{2}\right)$ & $U_{33}\left(\AA^{2}\right)$ & $U_{12}\left(\AA^{2}\right)$ & $U_{13}\left(\AA^{2}\right)$ & $U_{23}\left(\AA^{2}\right)$ \\
\hline$\overline{\text { Eu1 }}$ & $0.0088(4)$ & $0.00441(17)$ & $0.0063(5)$ & 0.0000 & 0.0000 & $-0.0010(2)$ \\
\hline Eu2 & $0.0060(5)$ & $0.0118(6)$ & $0.0034(6)$ & $-0.00010(18)$ & $-0.0010(3)$ & $0.0018(2)$ \\
\hline Eu3 & $0.0076(6)$ & $0.0011(2)$ & $0.0053(6)$ & 0.0000 & 0.0000 & $0.0004(2)$ \\
\hline Ca1 & $0.0056(5)$ & $0.0015(2)$ & $0.0033(7)$ & 0.0000 & 0.0000 & $-0.0014(2)$ \\
\hline $\mathrm{Ca} 2$ & $0.0158(5)$ & $0.0102(7)$ & $0.0059(8)$ & $0.0011(2)$ & $0.0010(3)$ & $-0.0003(4)$ \\
\hline $\mathrm{Ca} 3$ & $0.0087(3)$ & $0.00131(19)$ & $0.0059(4)$ & 0.0000 & 0.0000 & $0.00096(17)$ \\
\hline Mn1 & $0.0017(2)$ & $0.00518(19)$ & $0.0065(6)$ & $-0.00023(5)$ & $-0.0001(2)$ & $-0.0001(2)$ \\
\hline $\mathrm{Mn} 2$ & $0.0053(3)$ & $0.00314(16)$ & $0.0046(6)$ & 0.0000 & 0.0000 & $-0.0005(2)$ \\
\hline O1 & $0.0080(3)$ & $0.0080(4)$ & $0.0184(10)$ & $-0.0038(2)$ & $0.0027(6)$ & $-0.0001(4)$ \\
\hline $\mathrm{O} 2$ & $0.0092(3)$ & $0.0142(4)$ & $0.0154(10)$ & $-0.0005(2)$ & $0.0031(8)$ & $-0.0002(5)$ \\
\hline O3 & $0.0239(11)$ & $0.0139(8)$ & $0.0010(12)$ & 0.0000 & 0.0000 & $-0.0002(5)$ \\
\hline $\mathrm{O} 4$ & $0.0222(12)$ & $0.0145(7)$ & $0.0040(16)$ & 0.0000 & 0.0000 & $0.0014(7)$ \\
\hline O5 & $0.0325(14)$ & $0.0204(13)$ & $0.0087(15)$ & $-0.0014(4)$ & $-0.0012(5)$ & $0.0044(8)$ \\
\hline
\end{tabular}


TABLE VII: Distortion of $\mathrm{MnO}_{6}$ octahedra in $\mathrm{Eu}_{0.5} \mathrm{Ca}_{1.5} \mathrm{MnO}_{4}$ at $360 \mathrm{~K}$ (disordered phase) and $295 \mathrm{~K}$ (ordered phase).

\begin{tabular}{ccccccccc}
\hline \hline $360 \mathrm{~K}$ & $d_{x}\left(\AA^{2}\right)$ & $d_{y}\left(\AA^{2}\right)$ & $d_{z}\left(\AA^{2}\right)$ & $Q_{1}$ & $Q_{2}$ & $Q_{3}$ & $V$ \\
\hline Mn1 & $1.9098(4)$ & $1.9098(4)$ & $1.9556(9)$ & $-0.054(2)$ & $0.000(2)$ & $0.037(2)$ & $3.78(2)$ \\
\hline \hline $295 \mathrm{~K}$ & $d_{x}\left(\AA^{2}\right)$ & $d_{y}\left(\AA^{2}\right)$ & $d_{z}\left(\AA^{2}\right)$ & $Q_{1}$ & $Q_{2}$ & $Q_{3}$ & $V$ \\
\hline Mn1 & $1.943(4)$ & $1.863(3)$ & $1.972(5)$ & $-0.052(3)$ & $0.057(3)$ & $0.056(3)$ & $3.77(2)$ & $45(3)^{\circ}$ \\
Mn2 & $1.910(5)$ & $1.910(5)$ & $1.934(4)$ & $-0.066(3)$ & $0.000(3)$ & $0.019(3)$ & $3.85(2)$ & $0(1) \times 10^{\circ}$ \\
\hline \hline
\end{tabular}

TABLE VIII: The structure parameters of $\operatorname{Pr}\left(\mathrm{Sr}_{0.1} \mathrm{Ca}_{0.9}\right)_{2} \mathrm{Mn}_{2} \mathrm{O}_{7}$ in the disordered phase at $405 \mathrm{~K}$. The 6074 reflections were observed, and 2088 of them are independent. The 48 variables were used for the refinement. The space group is Amam (No. 63 ) of orthorhombic crystal system. The latticce parameters are as follows: $a=5.4080(5) \AA, b=5.4599(5) \AA, c=19.266(3) \AA$. The reliability factors are $R=3.42 \%, R_{w}=4.31 \%, \mathrm{GOF}=1.088$.

\begin{tabular}{|c|c|c|c|c|c|c|}
\hline & site & $x$ & $y$ & $z$ & $g$ & $B\left(\AA^{2}\right)$ \\
\hline$\overline{P r 1}$ & $8 g$ & $3 / 4$ & $0.2375(6)$ & $0.1844(2)$ & 0.21 & $0.86(2)$ \\
\hline Pr2 & $4 c$ & $3 / 4$ & $0.25011(18)$ & 0 & 0.58 & $0.763(16)$ \\
\hline Sr1 & $8 g$ & $3 / 4$ & $0.2413(5)$ & $0.1833(2)$ & 0.08 & $0.73(2)$ \\
\hline $\mathrm{Sr} 2$ & $4 c$ & $3 / 4$ & $0.2523(8)$ & 0 & 0.04 & $1.11(7)$ \\
\hline Ca1 & $8 g$ & $3 / 4$ & $0.2413(5)$ & $0.1833(2)$ & 0.71 & $0.73(2)$ \\
\hline $\mathrm{Ca} 2$ & $4 c$ & $3 / 4$ & $0.2523(8)$ & 0 & 0.38 & $1.11(7)$ \\
\hline $\mathrm{Mn}$ & $8 g$ & $3 / 4$ & $0.74812(2)$ & $0.09956(2)$ & 1 & $0.484(3)$ \\
\hline $\mathrm{O} 1$ & $8 e$ & 0 & $1 / 2$ & $0.10744(12)$ & 1 & $1.42(2)$ \\
\hline $\mathrm{O} 2$ & $8 e$ & 0 & 0 & $0.08776(11)$ & 1 & $1.33(2)$ \\
\hline O3 & $8 g$ & $3 / 4$ & $0.7950(2)$ & $0.19846(11)$ & 1 & $1.37(2)$ \\
\hline \multirow[t]{2}{*}{$\mathrm{O} 4$} & $4 c$ & $3 / 4$ & $0.6950(4)$ & 0 & 1 & $1.52(4)$ \\
\hline & $U_{11}\left(\AA^{2}\right)$ & $U_{22}\left(\AA^{2}\right)$ & $U_{33}\left(\AA^{2}\right)$ & $U_{12}\left(\AA^{2}\right)$ & $U_{13}\left(\AA^{2}\right)$ & $\overline{U_{23}\left(\AA^{2}\right)}$ \\
\hline$\overline{\operatorname{Pr} 1}$ & $0.0156(7)$ & $0.0111(4)$ & $0.0059(13)$ & 0.0000 & 0.0000 & $0.0006(5)$ \\
\hline $\operatorname{Pr} 2$ & $0.0126(3)$ & $0.0106(2)$ & $0.0059(6)$ & 0.0000 & 0.0000 & 0.0000 \\
\hline Sr1 & $0.0087(10)$ & $0.0103(3)$ & $0.0087(3)$ & 0.0000 & 0.0000 & $0.0005(4)$ \\
\hline Sr2 & $0.0062(9)$ & $0.0096(10)$ & $0.026(3)$ & 0.0000 & 0.0000 & 0.0000 \\
\hline Ca1 & $0.0087(10)$ & $0.0103(3)$ & $0.0087(3)$ & 0.0000 & 0.0000 & $0.0005(4)$ \\
\hline $\mathrm{Ca} 2$ & $0.0062(9)$ & $0.0096(10)$ & $0.026(3)$ & 0.0000 & 0.0000 & 0.0000 \\
\hline $\mathrm{Mn}$ & $0.00527(6)$ & $0.00597(5)$ & $0.00715(15)$ & 0.0000 & 0.0000 & $-0.00005(4)$ \\
\hline $\mathrm{O} 1$ & $0.0150(4)$ & $0.0164(3)$ & $0.0226(11)$ & $0.0062(2)$ & 0.0000 & 0.0000 \\
\hline $\mathrm{O} 2$ & $0.0158(4)$ & $0.0165(3)$ & $0.0182(11)$ & $-0.0046(3)$ & 0.0000 & 0.0000 \\
\hline $\mathrm{O} 3$ & $0.0263(6)$ & $0.0176(4)$ & $0.0080(10)$ & 0.0000 & 0.0000 & $-0.0008(4)$ \\
\hline $\mathrm{O} 4$ & $0.0325(10)$ & $0.0164(5)$ & $0.0090(14)$ & 0.0000 & 0.0000 & 0.0000 \\
\hline
\end{tabular}


TABLE IX: The structure parameters of $\operatorname{Pr}\left(\mathrm{Sr}_{0.1} \mathrm{Ca}_{0.9}\right)_{2} \mathrm{Mn}_{2} \mathrm{O}_{7}$ in the charge- and orbital-ordered phase (CO1) at $330 \mathrm{~K}$. The 25327 reflections were observed, and 8255 of them are independent. The 130 variables were used for the refinement. The space group is Pbnm (No. 62) of orthorhombic crystal system. The latticce parameters are as follows: $a=5.4087(2) \AA, b=10.9171(5)$ $\AA, c=19.2312(12) \AA$. The reliability factors are $R=3.35 R_{w}=4.52 \mathrm{GOF}=0.976$.

\begin{tabular}{|c|c|c|c|c|c|c|}
\hline & site & $x$ & $y$ & $z$ & $g$ & $B\left(\AA^{2}\right)$ \\
\hline$\overline{P r 1}$ & $8 d$ & $0.75725(3)$ & $0.74371(3)$ & $0.56534(3)$ & 0.21 & $0.66(3)$ \\
\hline $\operatorname{Pr} 2$ & $4 c$ & $0.260500(10)$ & $0.747320(10)$ & $1 / 4$ & 0.58 & $0.643(9)$ \\
\hline Pr3 & $4 c$ & $0.746400(10)$ & $0.498900(10)$ & $1 / 4$ & 0.58 & $0.787(16)$ \\
\hline $\operatorname{Pr} 4$ & $8 d$ & $0.74868(3)$ & $0.48804(3)$ & $0.06413(3)$ & 0.21 & $0.514(15)$ \\
\hline Sr1 & $8 d$ & $0.76207(3)$ & $0.74477(3)$ & $0.56679(3)$ & 0.08 & $0.73(2)$ \\
\hline $\mathrm{Sr} 2$ & $4 c$ & $0.255200(10)$ & $0.759300(10)$ & $1 / 4$ & 0.04 & $0.48(3)$ \\
\hline Sr3 & $4 c$ & $0.732000(10)$ & $0.502000(10)$ & $1 / 4$ & 0.04 & $0.43(3)$ \\
\hline $\mathrm{Sr} 4$ & $8 d$ & $0.74744(3)$ & $0.500610(3)$ & $0.06809(3)$ & 0.08 & $0.502(12)$ \\
\hline Ca1 & $8 d$ & $0.76207(3)$ & $0.74477(3)$ & $0.56679(3)$ & 0.71 & $0.73(2)$ \\
\hline $\mathrm{Ca} 2$ & $4 c$ & $0.255200(10)$ & $0.759300(10)$ & $1 / 4$ & 0.38 & $0.48(3)$ \\
\hline $\mathrm{Ca} 3$ & $4 c$ & $0.732000(10)$ & $0.502000(10)$ & $1 / 4$ & 0.38 & $0.43(3)$ \\
\hline $\mathrm{Ca} 4$ & $8 d$ & $0.74744(3)$ & $0.500610(3)$ & $0.06809(3)$ & 0.71 & $0.502(12)$ \\
\hline Mn1 & $8 d$ & $0.24701(4)$ & $0.50147(13)$ & $0.34933(6)$ & 1 & $0.431(8)$ \\
\hline Mn2 & $8 d$ & $0.75953(5)$ & $0.74929(12)$ & $0.34970(6)$ & 1 & $0.441(6)$ \\
\hline $\mathrm{O} 1$ & $8 d$ & $0.0096(6)$ & $0.6250(3)$ & $0.36026(11)$ & 1 & $1.20(2)$ \\
\hline $\mathrm{O} 2$ & $8 d$ & $0.5089(7)$ & $0.6264(3)$ & $0.35514(12)$ & 1 & $1.33(3)$ \\
\hline O3 & $4 c$ & $0.7685(5)$ & $0.7174(4)$ & $1 / 4$ & 1 & $1.06(4)$ \\
\hline $\mathrm{O} 4$ & $4 c$ & $0.2397(4)$ & $0.5220(5)$ & $1 / 4$ & 1 & $1.20(6)$ \\
\hline O5 & $8 d$ & $0.4858(5)$ & $0.3725(3)$ & $0.33750(12)$ & 1 & $1.08(2)$ \\
\hline O6 & $8 d$ & $0.9798(4)$ & $0.3707(2)$ & $0.33743(12)$ & 1 & $0.98(2)$ \\
\hline $\mathrm{O} 7$ & $8 d$ & $0.7516(3)$ & $0.7682(5)$ & $0.4461(2)$ & 1 & $1.23(5)$ \\
\hline \multirow[t]{2}{*}{$\mathrm{O} 8$} & $8 d$ & $0.2518(2)$ & $0.4731(4)$ & $0.4510(2)$ & 1 & $0.92(4)$ \\
\hline & $U_{11}\left(\AA^{2}\right)$ & $U_{22}\left(\AA^{2}\right)$ & $U_{33}\left(\AA^{2}\right)$ & $U_{12}\left(\AA^{2}\right)$ & $U_{13}\left(\AA^{2}\right)$ & $U_{23}\left(\AA^{2}\right)$ \\
\hline$\overline{P r 1}$ & $0.0153(5)$ & $0.0088(4)$ & $0.0012(14)$ & $-0.0021(3)$ & $0.0015(4)$ & $-0.0026(5)$ \\
\hline Pr2 & $0.01000(14)$ & $0.0062(3)$ & $0.0082(2)$ & $0.00099(9)$ & 0.0000 & 0.0000 \\
\hline Pr3 & $0.00978(18)$ & $0.0105(5)$ & $0.0096(5)$ & $0.00124(12)$ & 0.0000 & 0.0000 \\
\hline $\operatorname{Pr} 4$ & $0.0113(3)$ & $0.0040(2)$ & $0.0042(5)$ & $0.00077(10)$ & $-0.00017(11)$ & $-0.0025(2)$ \\
\hline Sr1 & $0.0074(2)$ & $0.0087(4)$ & $0.0117(9)$ & $0.0015(3)$ & $-0.0010(3)$ & $-0.0003(4)$ \\
\hline $\mathrm{Sr} 2$ & $0.0099(8)$ & $0.0011(7)$ & $0.0072(9)$ & $0.0014(3)$ & 0.0000 & 0.0000 \\
\hline Sr3 & $0.0055(3)$ & $0.0040(9)$ & $0.0067(10)$ & $0.0018(5)$ & 0.0000 & 0.0000 \\
\hline $\mathrm{Sr} 4$ & $0.00903(19)$ & $0.0041(2)$ & $0.0059(5)$ & $0.00071(7)$ & $0.00007(10)$ & $-0.0027(2)$ \\
\hline Ca1 & $0.0074(2)$ & $0.0087(4)$ & $0.0117(9)$ & $0.0015(3)$ & $-0.0010(3)$ & $-0.0003(4)$ \\
\hline $\mathrm{Ca} 2$ & $0.0099(8)$ & $0.0011(7)$ & $0.0072(9)$ & $0.0014(3)$ & 0.0000 & 0.0000 \\
\hline $\mathrm{Ca} 3$ & $0.0055(3)$ & $0.0040(9)$ & $0.0067(10)$ & $0.0018(5)$ & 0.0000 & 0.0000 \\
\hline $\mathrm{Ca} 4$ & $0.00903(19)$ & $0.0041(2)$ & $0.0059(5)$ & $0.00071(7)$ & $0.00007(10)$ & $-0.0027(2)$ \\
\hline Mn1 & $0.00487(10)$ & $0.00486(18)$ & $0.0066(3)$ & $0.00036(4)$ & $0.00001(5)$ & $-0.00008(16)$ \\
\hline Mn2 & $0.00472(8)$ & $0.00536(17)$ & $0.0067(2)$ & $-0.00030(8)$ & $-0.00026(7)$ & $-0.00017(16)$ \\
\hline $\mathrm{O} 1$ & $0.0112(5)$ & $0.0122(4)$ & $0.0224(9)$ & $0.0072(3)$ & $-0.0022(6)$ & $-0.0018(8)$ \\
\hline $\mathrm{O} 2$ & $0.0162(6)$ & $0.0156(5)$ & $0.0186(10)$ & $-0.0021(4)$ & $0.0002(7)$ & $-0.0020(10)$ \\
\hline O3 & $0.0253(10)$ & $0.0079(6)$ & $0.0070(17)$ & $0.0032(6)$ & 0.0000 & 0.0000 \\
\hline $\mathrm{O} 4$ & $0.0255(13)$ & $0.0164(14)$ & $0.0036(19)$ & $-0.0043(6)$ & 0.0000 & 0.0000 \\
\hline O5 & $0.0135(6)$ & $0.0113(4)$ & $0.0162(8)$ & $0.0048(4)$ & $0.0001(4)$ & $-0.0010(6)$ \\
\hline O6 & $0.0117(7)$ & $0.0111(5)$ & $0.0142(8)$ & $-0.0073(3)$ & $0.0013(4)$ & $-0.0004(5)$ \\
\hline $\mathrm{O} 7$ & $0.0212(9)$ & $0.0169(11)$ & $0.009(2)$ & $0.0001(3)$ & $-0.0001(3)$ & $-0.0071(12)$ \\
\hline $\mathrm{O} 8$ & $0.0239(9)$ & $0.0099(6)$ & $0.0014(19)$ & $0.0009(3)$ & $-0.0005(3)$ & $-0.0009(7)$ \\
\hline
\end{tabular}


TABLE X: The structure parameters of $\operatorname{Pr}\left(\mathrm{Sr}_{0.1} \mathrm{Ca}_{0.9}\right)_{2} \mathrm{Mn}_{2} \mathrm{O}_{7}$ in the charge- and orbital-ordered phase (CO2) at 295 K. The 13242 reflections were observed, and 8080 of them are independent. The 144 variables were used for the refinement. The space group is $A m 2 m$ (No.38) of orthorhombic crystal system. The latticce parameters are as follows: $a=10.8026(7) \AA, b=5.4719(4)$ $\AA, c=19.2090(10) \AA$. The reliability factors are $R=2.95 R_{w}=3.80 \mathrm{GOF}=1.027$.

\begin{tabular}{|c|c|c|c|c|c|c|}
\hline & site & $x$ & $y$ & $z$ & $g$ & $B\left(\AA^{2}\right)$ \\
\hline Pr1 & $8 f$ & $0.252310(10)$ & $0.762490(10)$ & $0.183810(10)$ & 0.21 & $0.556(17)$ \\
\hline $\operatorname{Pr} 2$ & $4 e$ & $1 / 2$ & $0.246830(10)$ & $0.185150(10)$ & 0.21 & $0.528(13)$ \\
\hline Pr3 & $4 d$ & 0 & $0.258500(10)$ & $0.183300(10)$ & 0.21 & $0.502(12)$ \\
\hline $\operatorname{Pr} 4$ & $4 c$ & $0.248560(10)$ & $0.757300(10)$ & 0 & 0.58 & $0.598(4)$ \\
\hline $\operatorname{Pr} 5$ & $2 b$ & $1 / 2$ & $0.249200(10)$ & 0 & 0.58 & $0.668(7)$ \\
\hline $\operatorname{Pr} 6$ & $2 a$ & 0 & $0.262900(10)$ & 0 & 0.58 & $0.646(7)$ \\
\hline Sr1 & $8 f$ & $0.249310(10)$ & $0.763690(10)$ & $0.183810(10)$ & 0.08 & $0.688(15)$ \\
\hline $\mathrm{Sr} 2$ & $4 e$ & $1 / 2$ & $0.219210(10)$ & $0.183490(10)$ & 0.08 & $0.485(6)$ \\
\hline Sr3 & $4 d$ & 0 & $0.244500(10)$ & $0.183700(10)$ & 0.08 & $0.669(17)$ \\
\hline $\mathrm{Sr} 4$ & $4 c$ & $0.243700(10)$ & $0.736500(10)$ & 0 & 0.04 & $0.55(2)$ \\
\hline Sr5 & $2 b$ & $1 / 2$ & $0.216600(10)$ & 0 & 0.04 & $0.354(14)$ \\
\hline Sr6 & $2 a$ & 0 & $0.274300(10)$ & 0 & 0.04 & $0.40(3)$ \\
\hline Ca1 & $8 f$ & $0.249310(10)$ & $0.763690(10)$ & $0.183810(10)$ & 0.71 & $0.688(15)$ \\
\hline $\mathrm{Ca} 2$ & $4 e$ & $1 / 2$ & $0.219210(10)$ & $0.183490(10)$ & 0.71 & $0.485(6)$ \\
\hline $\mathrm{Ca} 3$ & $4 d$ & 0 & $0.244500(10)$ & $0.183700(10)$ & 0.71 & $0.669(17)$ \\
\hline $\mathrm{Ca} 4$ & $4 c$ & $0.243700(10)$ & $0.736500(10)$ & 0 & 0.38 & $0.55(2)$ \\
\hline $\mathrm{Ca} 5$ & $2 b$ & $1 / 2$ & $0.216600(10)$ & 0 & 0.38 & $0.354(14)$ \\
\hline $\mathrm{Ca} 6$ & $2 a$ & 0 & $0.274300(10)$ & 0 & 0.38 & $0.40(3)$ \\
\hline Mn1 & $8 f$ & $0.25029(2)$ & $0.25753(12)$ & $0.09946(2)$ & 1 & $0.357(3)$ \\
\hline Mn2 & $4 e$ & $1 / 2$ & $0.74255(13)$ & $0.09886(3)$ & 1 & $0.461(7)$ \\
\hline Mn3 & $4 d$ & 0 & $0.76417(13)$ & $0.10010(2)$ & 1 & $0.326(4)$ \\
\hline $\mathrm{O} 1$ & $8 f$ & $0.1224(2)$ & $0.0199(3)$ & $0.60700(9)$ & 1 & $1.18(2)$ \\
\hline $\mathrm{O} 2$ & $8 f$ & $0.3764(2)$ & $0.9883(3)$ & $0.39083(9)$ & 1 & $1.129(18)$ \\
\hline O3 & $8 f$ & $0.1245(2)$ & $0.0116(4)$ & $0.08692(7)$ & 1 & $1.007(16)$ \\
\hline $\mathrm{O} 4$ & $8 f$ & $0.3775(2)$ & $0.9789(3)$ & $0.91264(7)$ & 1 & $0.982(19)$ \\
\hline O5 & $8 f$ & $0.24888(12)$ & $0.2069(4)$ & $0.19839(15)$ & 1 & $1.07(3)$ \\
\hline $\mathrm{O} 6$ & $4 e$ & $1 / 2$ & $0.7902(4)$ & $0.19831(17)$ & 1 & $1.11(3)$ \\
\hline $\mathrm{O} 7$ & $4 d$ & 0 & $0.8081(4)$ & $0.19837(17)$ & 1 & $1.21(3)$ \\
\hline $\mathrm{O} 8$ & $4 c$ & $0.25303(19)$ & $0.3097(5)$ & 0 & 1 & $1.10(4)$ \\
\hline O9 & $2 b$ & $1 / 2$ & $0.6791(7)$ & 0 & 1 & $1.34(5)$ \\
\hline \multirow[t]{2}{*}{ O10 } & $2 a$ & 0 & $0.7105(6)$ & 0 & 1 & $1.02(4)$ \\
\hline & $U_{11}\left(\AA^{2}\right)$ & $U_{22}\left(\AA^{2}\right)$ & $U_{33}\left(\AA^{2}\right)$ & $U_{12}\left(\AA^{2}\right)$ & $U_{13}\left(\AA^{2}\right)$ & $U_{23}\left(\AA^{2}\right)$ \\
\hline$\overline{P r 1}$ & $0.0084(4)$ & $0.0064(4)$ & $0.0063(4)$ & $-0.0006(3)$ & $0.0022(2)$ & $-0.0009(3)$ \\
\hline $\operatorname{Pr} 2$ & $0.0053(2)$ & $0.0080(4)$ & $0.0067(2)$ & 0.0000 & 0.0000 & $-0.00100(19)$ \\
\hline Pr3 & $0.0089(4)$ & $0.0049(2)$ & $0.0053(2)$ & 0.0000 & 0.0000 & $0.0009(2)$ \\
\hline $\operatorname{Pr} 4$ & $0.00851(15)$ & $0.00681(9)$ & $0.00739(11)$ & $-0.00027(9)$ & 0.0000 & 0.0000 \\
\hline $\operatorname{Pr} 5$ & $0.01083(16)$ & $0.0062(2)$ & $0.00835(17)$ & 0.0000 & 0.0000 & 0.0000 \\
\hline Pr6 & $0.0113(2)$ & $0.00492(18)$ & $0.0084(2)$ & 0.0000 & 0.0000 & 0.0000 \\
\hline Sr1 & $0.0134(4)$ & $0.0068(4)$ & $0.0060(3)$ & $0.0000(3)$ & $-0.0017(2)$ & $-0.0003(2)$ \\
\hline $\mathrm{Sr} 2$ & $0.01022(19)$ & $0.00283(17)$ & $0.00537(15)$ & 0.0000 & 0.0000 & $-0.00047(12)$ \\
\hline Sr3 & $0.0072(4)$ & $0.0127(5)$ & $0.0055(3)$ & 0.0000 & 0.0000 & $-0.0006(2)$ \\
\hline $\mathrm{Sr} 4$ & $0.0052(4)$ & $0.0100(6)$ & $0.0056(4)$ & $-0.0040(4)$ & 0.0000 & 0.0000 \\
\hline Sr5 & - & - & - & - & - & - \\
\hline Sr6 & - & - & - & - & - & - \\
\hline Ca1 & $0.0134(4)$ & $0.0068(4)$ & $0.0060(3)$ & $0.0000(3)$ & $-0.0017(2)$ & $-0.0003(2)$ \\
\hline $\mathrm{Ca} 2$ & $0.01022(19)$ & $0.00283(17)$ & $0.00537(15)$ & 0.0000 & 0.0000 & $-0.00047(12)$ \\
\hline $\mathrm{Ca} 3$ & $0.0072(4)$ & $0.0127(5)$ & $0.0055(3)$ & 0.0000 & 0.0000 & $-0.0006(2)$ \\
\hline $\mathrm{Ca} 4$ & $0.0052(4)$ & $0.0100(6)$ & $0.0056(4)$ & $-0.0040(4)$ & 0.0000 & 0.0000 \\
\hline Ca5 & - & - & - & - & - & - \\
\hline $\mathrm{Ca} 6$ & - & - & - & - & - & - \\
\hline Mn1 & $0.00380(9)$ & $0.00412(9)$ & $0.00563(10)$ & $-0.00053(3)$ & $0.00006(4)$ & $0.00053(10)$ \\
\hline Mn2 & $0.00391(14)$ & $0.0081(2)$ & $0.00546(16)$ & 0.0000 & 0.0000 & $0.00078(10)$ \\
\hline Mn3 & $0.00420(10)$ & $0.00277(11)$ & $0.00540(11)$ & 0.0000 & 0.0000 & $0.00018(11)$ \\
\hline $\mathrm{O} 1$ & $0.0110(4)$ & $0.0148(6)$ & $0.0189(4)$ & $0.0045(3)$ & $0.0003(6)$ & $0.0024(4)$ \\
\hline $\mathrm{O} 2$ & $0.0113(4)$ & $0.0123(4)$ & $0.0193(4)$ & $-0.0069(3)$ & $0.0008(5)$ & $-0.0030(4)$ \\
\hline O3 & $0.0104(3)$ & $0.0132(5)$ & $0.0146(3)$ & $-0.0067(3)$ & $-0.0003(4)$ & $-0.0020(4)$ \\
\hline $\mathrm{O} 4$ & $0.0118(4)$ & $0.0118(6)$ & $0.0137(4)$ & $0.0052(3)$ & $0.0003(3)$ & $0.0003(3)$ \\
\hline O5 & $0.0196(9)$ & $0.0153(7)$ & $0.0056(7)$ & $-0.0007(3)$ & $0.0005(2)$ & $-0.0029(5)$ \\
\hline $\mathrm{O} 6$ & $0.0220(11)$ & $0.0142(8)$ & $0.0059(7)$ & 0.0000 & 0.0000 & $-0.0031(6)$ \\
\hline O7 & $0.0262(12)$ & $0.0137(9)$ & $0.0060(8)$ & 0.0000 & 0.0000 & $-0.0025(5)$ \\
\hline $\mathrm{O} 8$ & $0.0233(13)$ & $0.0127(9)$ & $0.0058(8)$ & $-0.0012(4)$ & 0.0000 & 0.0000 \\
\hline O9 & $0.0285(17)$ & $0.0181(14)$ & $0.0044(9)$ & 0.0000 & 0.0000 & 0.0000 \\
\hline O10 & $0.0219(14)$ & $0.0140(10)$ & $0.0029(7)$ & 0.0000 & 0.0000 & 0.0000 \\
\hline
\end{tabular}


TABLE XI: Distortion of $\mathrm{MnO}_{6}$ octahedra at $405 \mathrm{~K}, 330 \mathrm{~K}$, and $295 \mathrm{~K}$ of $\operatorname{Pr}\left(\mathrm{Sr}_{0.1} \mathrm{Ca}_{0.9}\right)_{2} \mathrm{Mn}_{2} \mathrm{O}_{7}$.

\begin{tabular}{|c|c|c|c|c|c|c|c|c|}
\hline $405 \mathrm{~K}$ & $d_{x}\left(\AA^{2}\right)$ & $d_{y}\left(\AA^{2}\right)$ & $d_{z}\left(\AA^{2}\right)$ & $Q_{1}$ & $Q_{2}$ & $Q_{3}$ & $V$ & $\theta$ \\
\hline Mn1 & $1.9309(3)$ & $1.9309(3)$ & $1.931(2)$ & $-0.043(2)$ & $0.000(2)$ & $0.000(2)$ & $3.72(2)$ & $0^{\circ}$ \\
\hline $330 \mathrm{~K}$ & $d_{x}\left(\AA^{2}\right)$ & $d_{y}\left(\AA^{2}\right)$ & $d_{z}\left(\AA^{2}\right)$ & $Q_{1}$ & $Q_{2}$ & $Q_{3}$ & $V$ & $\theta$ \\
\hline Mn2 & $1.898(4)$ & $1.925(5)$ & $1.908(4)$ & $-0.080(3)$ & $0.019(3)$ & $-0.003(3)$ & $3.92(2)$ & $10(1) \times 10^{\circ}$ \\
\hline $295 \mathrm{~K}$ & $d_{x}\left(\AA^{2}\right)$ & $d_{y}\left(\AA^{2}\right)$ & $d_{z}\left(\AA^{2}\right)$ & $Q_{1}$ & $Q_{2}$ & $Q_{3}$ & $V$ & $\theta$ \\
\hline Mn3 & $1.905(2)$ & $1.905(2)$ & $1.924(3)$ & $-0.077(2)$ & $0.000(2)$ & $0.016(2)$ & $3.91(2)$ & $0(8)^{\circ}$ \\
\hline
\end{tabular}

